\title{
MARKETING SOCIAL E MARKETING SOCIETAL: UMA CONFUSÃO TEÓRICA
}

\author{
SOCIAL MARKETING AND SOCIETAL MARKETING: A \\ THEORETICAL CONFUSION
}

\section{MARKETING SOCIAL Y MARKETING SOCIETAL: UNA CONFUSIÓN TEÓRICA}

Taís Pasquotto Andreoli

Mestra em Administração - FEA/USP, São

Paulo, Brasil / Doutoranda em Administração

- USCS, São Caetano do Sul, Brasil

tais_pa@hotmail.com

Váldeson Amaro Lima

Mestre em Administração - UNIR, Porto

Velho, Brasil / Doutorando em Administração

- USCS, São Caetano do Sul, Brasil /

Professor EBTT Administração - IFRO, Porto

Velho, Brasil

valdeson.lima@ifro.edu.br

\section{Silvio Augusto Minciotti}

Doutor em Administração - FEA/USP, São

Paulo, Brasil / Professor no PPGA - USCS,

São Caetano do Sul, Brasil

silvio.minciotti@uscs.edu.br
Contextus

ISSNe 2178-9258

Organização: Comitê Científico Interinstitucional Editor Científico: Diego de Queiroz Machado

Editor Executivo: Carlos Daniel Andrade

Avaliação: double blind review pelo SEER/OJS

Recebido em 23/08/2017

Aceito em 11/04/2018

$2^{2}$ versão aceita em 03/05/2018

\section{RESUMO}

Apesar da clara distinção entre os conceitos de marketing social e marketing societal, ainda é recorrente uma acepção errônea desses termos. Nesse sentido, o trabalho teve como objetivos: (1) mapear a produção acadêmica em relação aos temas do marketing social e marketing societal; e, principalmente, (2) verificar e analisar possíveis distorções no emprego desses termos. Foram feitos: um levantamento bibliográfico com o intuito de estudar as circunstâncias em que se originaram ambos os temas; e uma pesquisa bibliométrica associada a uma análise crítica dos conteúdos das publicações acadêmicas identificadas com os termos marketing social e marketing societal. Foi possível observar que, apesar da expressiva produção científica identificada, são notórias as distorções no emprego dos termos supracitados, seja ao apresentar os conceitos de forma equivocada, seja ao expressar uma acepção incorreta ou mesmo ao aplicá-los de forma indevida.

Palavras-chave: Marketing social; Marketing societal; Evolução do marketing; Desconformidades em marketing; Tipos de marketing.

\footnotetext{
ABSTRACT

Despite a clear distinction between the concepts of social marketing and societal marketing, a misguided usage of these terms keeps on recurring. In this sense, the work aimed at: (1) mapping the academic production concerning social marketing and societal marketing; and, in particular, (2) checking and analyzing possible distortions around their use. A bibliographic survey was developed in order to study the circumstances in which those themes arose; also, a bibliometric research was carried out together with a critical analysis of academic publications' contents referring to social marketing and societal marketing. It was possible to observe that, in spite of the expressive scientific production identified, there are remarkable distortions in the usage of the above mentioned terms, whether while presenting the concepts in a mistaken way or while expressing an incorrect meaning of them or even while applying them in an improper way.

Keywords: Social marketing; Societal marketing; Evolution of marketing; Nonconformities in marketing; Types of marketing.
} 


\section{RESUMEN}

A pesar de la clara distinción entre los conceptos de marketing social y marketing societal, sigue ocurriendo el empleo erróneo de estos términos. En este sentido, el objetivo del estudio fue: (1) mapeo de la literatura académica sobre los temas de marketing social y de marketing societal, y en especial (2) verificar y analizar las posibles distorsiones sobre el uso de estos términos. Se elaboró un levantamiento bibliográfico con el propósito de estudiar las circunstancias en que se originaron los temas y una investigación bibliométrica asociada a un análisis crítico de los contenidos de las publicaciones académicas identificadas con los términos marketing social y marketing societal. Es posible observar que, a pesar de la expresiva producción científica identificada, son notorias las distorsiones en el empleo de los términos arriba citados, sea al presentar los conceptos de forma equivocada, al expresar una acepción incorrecta o mismo al aplicarlos de forma insuficiente.

Palabras clave: Marketing social; marketing societal; Evolución del marketing; Inconformidad en marketing; Tipos de marketing.

\section{INTRODUÇÃO}

À medida que o marketing se aplicava a atividades específicas, era classificado de modo a explicitar as aplicações. Configuram-se como exemplos bastante conhecidos das classificações o marketing de serviços, o esportivo, o interno, o social, dentre tantos outros.

Dadas as diferenças de aplicação, o marketing social pode ser definido como aquele que se apropria dos conhecimentos e técnicas mercadológicas, adaptando-os e os colocando a serviço da implementação, promoção e difusão de causas sociais, tendo em vista o bem-estar da sociedade (SILVA; MINCIOTTI; GIL, 2013). Outra forma de definir o marketing social enfatiza sua finalidade de mudar o comportamento dos indivíduos alcançados pelas causas sociais (MARTINS et al., 2014; BARBOZA; COSTA, 2014). Retomando sua origem, ele foi definido por Kotler (1978, p. 288) como “o projeto, a implementação e o controle de programas que procuram aumentar a aceitação de uma ideia ou prática social num grupo-alvo". Também se caracteriza, segundo o mesmo autor, por utilizar conceitos de segmentação de mercado, de pesquisa junto aos públicos-alvo e de tudo relativo à formulação estratégica do composto de marketing.

Por outro lado, devido às novas circunstâncias do ambiente em que atua, o marketing vem desenvolvendo uma nova filosofia, capaz de abarcar as demandas do novo contexto empresarial, principalmente relacionadas à cobrança de uma postura mais socialmente responsável das organizações (SILVA; MINCIOTTI; ROMEIRO, 2011). A essa nova abordagem deu-se o nome de marketing societal, entendido como uma filosofia organizacional em consonância com a ética e os valores sociais (SILVA; MINCIOTTI, 2005), cuja preocupação se estende além do objetivo de apenas satisfazer os consumidores, para também abarcar uma preocupação com as necessidades da sociedade em geral (SCHNEIDER; LUCE, 
2014). O marketing societal, voltado a ações adotadas por empresas nos relacionamentos com seus consumidores, busca principalmente minimizar o impacto do composto de marketing daquelas (o marketing mix) sobre o ambiente de consumo.

Assim, fica claro que o marketing social e o societal consistem em conceitos muito distintos. Apesar disso e da considerável produção científica acerca desses temas, ainda é recorrente uma acepção errônea dos termos (TAVARES; ESPANHA, 2015), muitas vezes confundidos, quando não tidos como sinônimos (SILVA; MINCIOTTI; GIL, 2013; SCHNEIDER; LUCE, 2014; BERGEL et al., 2015).

À luz do exposto, o trabalho teve como objetivos: (1) mapear a produção acadêmica sobre marketing social e societal, bem como, principalmente, (2) verificar possíveis distorções acerca do emprego dos termos. Com tais propósitos, elaborou-se um levantamento bibliográfico com o intuito de estudar as circunstâncias em que se originou a pesquisa dos dois conceitos e empreendeu-se uma pesquisa bibliométrica para analisar criticamente os conteúdos dos textos identificados, tendo como alvo as publicações acadêmicas acerca dos termos, nas bases científicas mais reconhecidas mundialmente (Proquest, Web of Science, Capes, Scopus, Scielo e Spell).

\section{MARKETING SOCIAL: UMA APLICAÇÃO DE MARKETING}

Com a publicação do artigo "Broadening the Concept of Marketing”, de Kotler e Levy (1969a), percebeu-se o início de uma nova fase na história do marketing. Introduziu-se a ideia de que este era aplicável a qualquer situação marcada por uma troca, independentemente da existência do lucro monetário na transação. O entendimento de lucro passou a ser um ganho, vantagem ou benefício, tangível ou intangível, que se pode obter de alguma coisa, de alguma troca ou de uma atividade qualquer. Desde a publicação do artigo, inúmeras críticas foram deflagradas contestando, principalmente, o que se convencionou chamar de marketing social a aplicação do marketing às causas sociais.

A primeira delas ocorreu imediatamente, em julho de 1969, no mesmo periódico, com a nota "Broadening the Concept of Marketing - Too Far", em que Luck (1969) expressa sua discordância da aplicação do marketing a qualquer outra atividade fora a comercial, uma vez que, para ele, o marketing foi concebido, exclusivamente, para tal fim e essa expansão 
acarretaria severas críticas dos executivos das empresas e dos sociólogos, comprometendo a imagem e o desenvolvimento da atividade. Nas páginas seguintes da mesma edição, o Journal of Marketing publica a nota A New Form of Marketing Myopia: rejoinder to Professor Luck, de autoria de Kotler e Levy (1969b), rechaçando a posição de Luck e reforçando os argumentos apresentados no primeiro artigo.

A origem do termo marketing social está vinculada ao artigo seminal de Kotler e Zaltman (1971) - Social Marketing: an approach to planned social change, no qual os autores dão ênfase ao fato de o marketing social ir muito além da propaganda ou de qualquer outra forma isolada de comunicação social voltada às causas ou ideias sociais, devendo ser entendido como "a criação, implementação e controle de programas calculados para influenciar a aceitação de ideias sociais e envolvendo considerações de planejamento, precificação, comunicação e distribuição de produtos e pesquisa de marketing" (KOTLER; ZALTMAN, 1971, p. 5).

No entanto, ao mesmo tempo em que o artigo contribuiu para estabelecer uma nova disciplina do marketing, fez aflorar certa discordância de alguns autores sobre aplicar o marketing às causas sociais (LUCK, 1974). Essa divergência decorreu principalmente das não evidentes diferenças entre os modelos de marketing social e tradicional, este também denominado comercial ou ortodoxo, bem como dos crescentes questionamentos sobre implicações éticas da aplicação do marketing social (LACZNIAK; LUSCH; MURPHY, 1979). Uma das causas do questionamento era, também, a dificuldade de distinguir, de um lado, o que seria uma causa social legitimada pela sociedade e, do outro, o que poderia ser uma ação manipuladora da opinião pública para fazer valer interesses políticos, ideológicos ou até mesmo econômicos de grupos específicos, com interesses por vezes espúrios.

Bloom e Novelli (1981) realizaram um estudo dos dez anos do surgimento do marketing social e, analisando os resultados, apontaram a ausência de rigor ao aplicar os princípios e técnicas de marketing em áreas como pesquisa, segmentação e canais de distribuição no marketing social (KOTLER; LEE, 2010). Já indicaram, naquela época, o possível surgimento de problemas ao tentar-se usar abordagens de livros didáticos convencionais em programas de marketing social (BLOOM; NOVELLI, 1981). O que então já se constatava era o entendimento equivocado de que o marketing social poderia se resumir às ações promocionais, com ênfase na propaganda, quando, na realidade, a pesquisa de mercado, a identificação dos públicos-alvo, 
o posicionamento e a adequada formulação das estratégias das variáveis que integram o composto de marketing são imprescindíveis para atingir os objetivos propostos.

Posteriormente, Andreasen (1994 apud TAVARES; ESPANHA, 2015) foi o responsável por refinar a definição de marketing social, conceituando-o como a aplicação de tecnologias de marketing tradicional para analisar, planejar, executar e avaliar programas sociais desenhados para influenciar o comportamento dos indivíduos-alvo, de modo a melhorar o bem-estar individual e coletivo. Em seguida, McKenzie-Mohr e Smith (1999) ampliaram o campo de discussão, sugerindo aplicar o marketing social a organizações de base comunitária, o que, em princípio, foge da proposta inicial de Kotler, por envolver uma organização sem fins lucrativos e não uma causa social. Por seu turno, Andreasen (2006) propôs, ainda, uma maior aplicação dos princípios do marketing social para a agenda pública, confirmando a possibilidade de aplicar o marketing em qualquer processo de troca.

Com base nesses estudos, convencionou-se denominar o marketing social como um processo que se utiliza dos princípios e técnicas do marketing comercial (ortodoxo) para análise, planejamento, execução e avaliação de programas destinados a criar, comunicar e fornecer valor a fim de influenciar o comportamento voluntário de públicos-alvo, provocando uma mudança comportamental benéfica à sociedade e/ou ao próprio público-alvo envolvido (ANDREASEN, 2006; KOTLER; LEE, 2010; BARBOZA; COSTA, 2014). Conforme fica claro, o marketing social se apropria, assim, de conhecimentos e técnicas mercadológicas, adaptando-os e aplicando-os à promoção e difusão de causas sociais (SILVA; MINCIOTTI; GIL, 2013).

Fundamentalmente, evidencia-se também a finalidade do marketing social: a mudança de comportamento dos indivíduos-alvo das causas sociais (MARTINS et al., 2014; BARBOZA; COSTA, 2014). Acerca disso, Tavares e Espanha (2015) argumentam que o propósito do marketing social não se limita a disseminar informações e ideias, mas sim a influenciar mudanças reais de comportamento, não devendo, por isso, confundir-se com educação e/ou propaganda. Kotler e Keller (2012, p. 695) contribuem para esse entendimento quando afirmam: "as campanhas de marketing social podem ter como objetivo mudar a capacidade cognitiva, os valores, as ações ou os comportamentos das pessoas".

Ainda nessa linha, Silva e Mazzon (2016) defendem que o marketing social é pouco eficaz quando limitado ao objetivo de apenas educar ou sensibilizar, sendo adequado, porém, se a educação e a tomada de consciência do indivíduo resultarem em mudança de comportamento e consequente mudança social direcionada a um público-alvo. Como 
consequência, pode-se dizer que a principal contribuição do marketing social decorre da percepção de valor que o indivíduo é influenciado a ter sobre adotar um comportamento estimulado, fundamental para concretizar a mudança social desejada (BARBOZA; COSTA, 2014).

Como resultado dessa discussão, Silva e Minciotti (2005) asseguram que existem limites muito precisos entre o marketing social e o marketing tradicional. Apesar disso, parece permanecer ainda na academia certa confusão acerca das fronteiras entre esses termos. Ademais, surgem novos conceitos associados ao marketing, como é o caso do marketing societal, capaz de potencializar a possibilidade de distorções do conceito de marketing e suas vertentes.

\section{MARKETING SOCIETAL: UMA EVOLUÇÃO CONCEITUAL}

As reflexões sobre o impacto do marketing sobre a sociedade remontam também à década de 1970, com o importante trabalho de Lavidge (1970) enfatizando mudanças em andamento na época, relacionadas ao conceito tradicional de marketing. Conforme se salientou, o papel dos profissionais de marketing até então, ao avaliar as oportunidades de novos produtos, tinham se concentrado, em grande parte, meramente sobre a possibilidade de suas vendas. Dessa forma, Lavidge (1970) indicou que, a partir dos anos 1970, haveria cada vez mais atenção não só sobre esse questionamento, mas também uma reflexão acerca dos custos da possibilidade e do impacto de comercializar esses produtos sobre a sociedade.

De modo similar, Feldman (1971) avaliou que a continuação das pressões do marketing tradicional sob níveis materialistas de consumo resultaria em benefícios individuais de curto prazo, mas poderia vir a sobrecarregar os recursos da sociedade no longo prazo, talvez ao ponto de ruptura. Nesse sentido, segundo afirma Takas (1974), o marketing tradicional, ao desconsiderar os impactos do consumo e os fatores que cada vez mais pressionam e preocupam o futuro da sociedade, deveria reconhecer-se como atividade míope, simplesmente fora de sintonia com a realidade de amanhã. Feldman (1971) defende como possível solução que o marketing, ao deslocar a ênfase para o "consumo não material” e considerações sociais, estaria agindo rumo aos interesses de longo prazo da sociedade e facilitaria a preservação de sua liberdade de ação futura. 
Como consequência, tem início uma importante revisão conceitual de marketing no meio acadêmico, levando Kotler (1978) a afirmar, pioneiramente, que o marketing societal se orienta para a satisfação e o bem-estar dos consumidores a longo prazo como meio para atingir os objetivos organizacionais. Pode-se observar que tal concepção se alinha com um perfil mercadológico, voltado para o lucro, porém mais evoluído na medida em que preocupa com a sociedade e com os impactos a ela causados pelas atividades organizacionais, em especial as mercadológicas (SILVA; MINCIOTTI, 2005).

O marketing societal reflete, portanto, uma forma de pensar e posicionar a empresa em seus mercados de atuação, frente aos desafios comerciais que lhes são apresentados, principalmente devido à evolução dos mercados e do perfil dos consumidores, mais esclarecidos e conscientes (MORAIS et al., 2005). Nesse sentido, pretendeu-se romper com a visão restrita de buscar satisfazer quer os desejos mais imediatos dos consumidores, quer o objetivo de maior lucratividade dos seus acionistas.

Como alternativa, o marketing societal propõe alcançar essas metas pautado pela consciência dos impactos que suas ações e o consumo dos seus produtos causam ao indivíduo e à sociedade no longo prazo. Trata-se, pois, de um aprimoramento do conceito de marketing, que estende a linha de pensamento ortodoxa para englobar toda uma conjuntura de fatores passíveis de causar danos ao indivíduo e à sociedade em decorrência do consumo desregrado de determinados produtos no longo prazo (SILVA; MINCIOTTI, 2005; BERGEL et al., 2015).

Por essa razão, Silva, Minciotti e Romeiro (2011) entendem que existe uma correlação entre desenvolvimento sustentável e marketing societal, representada pela Figura 1. Nesse sentido, os pilares do desenvolvimento sustentável e do marketing societal convergem para o longo prazo visando garantir a satisfação das necessidades de consumo, de forma ética, propiciando à empresa "fazer a coisa certa", com o propósito de garantir a sustentabilidade de seus próprios objetivos, porém estimulando a incorporação de aspectos sociais e éticos às atividades empresariais e de consumo. 
Figura 1 - Considerações subjacentes ao conceito de marketing societal e sustentabilidade

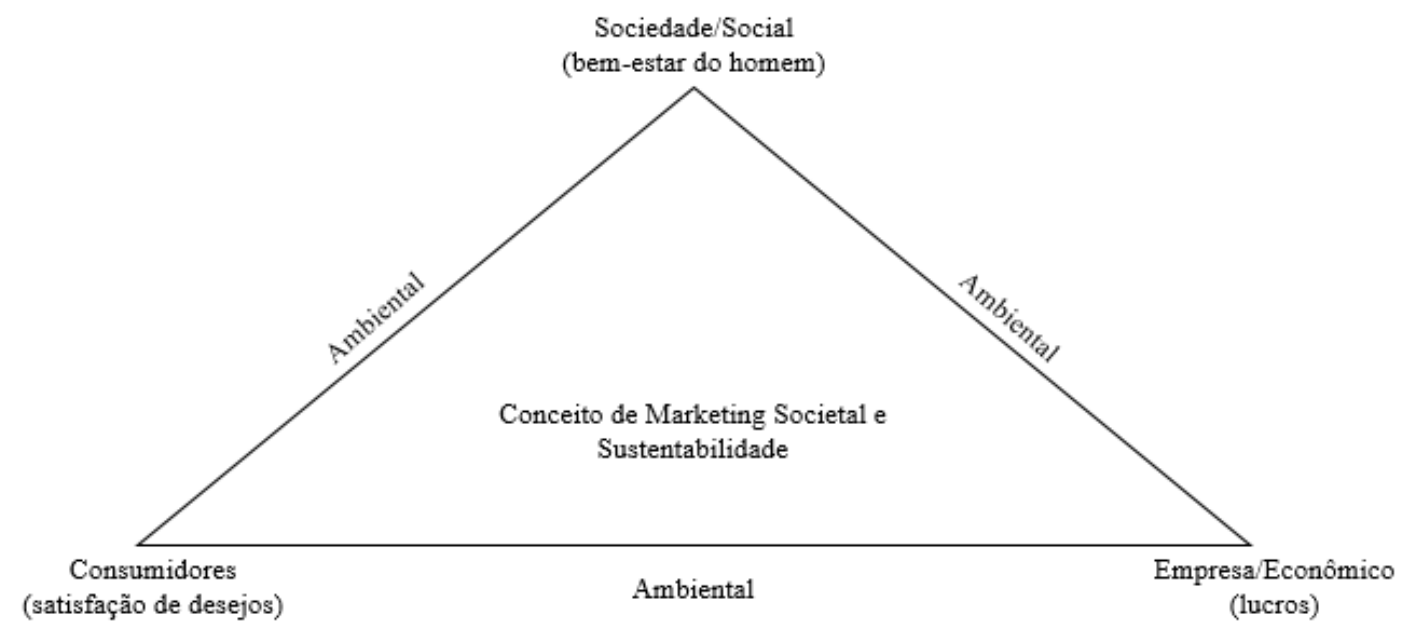

Fonte: adaptado de Silva, Minciotti e Romeiro (2011).

O conceito de marketing societal, portanto, exige das empresas o equilíbrio de três fatores ao definir uma política mercantil: a satisfação dos desejos dos consumidores, a lucratividade da empresa e o bem-estar do homem, não só no curto prazo, mas principalmente na análise do longo prazo (KOTLER; ARMSTROMG, 2007). Fechando esse entendimento, o fator desencadeador do marketing societal é o investimento social, orientado ao consumidor, com foco na aceitabilidade de produtos capazes de ser percebidos pelo valor gerado ao não interferir no bem-estar da sociedade (SILVA; MINCIOTTI; ROMEIRO, 2011).

\section{PROCEDIMENTOS METODOLÓGICOS}

Para alcançar os objetivos propostos, elaborou-se um levantamento bibliográfico com o intuito de estudar as circunstâncias de origem dos temas aqui em foco e uma pesquisa bibliométrica voltada a analisar criticamente os conteúdos dos textos identificados (TREINTA et al., 2014). O alvo foram as publicações acadêmicas em língua portuguesa acerca dos termos marketing social e marketing societal, desde suas origens, nas bases científicas com maior reconhecimento acadêmico da área de Ciências Sociais Aplicadas (Proquest, Web of Science, Capes, Scopus, Scielo e Spell). Esta pesquisa visou identificar as circunstâncias em que esses termos foram empregados nas publicações disponíveis nas principais bases de dados utilizadas no país. Com isso, foi possível desenvolver um mapeamento geral do que se tem produzido sobre os assuntos, no sentido de não só consolidar o estudado até então, mas, principalmente, apontar possíveis distorções acerca do termos. 
Considerando que uma das hipóteses que tratam da ambiguidade no uso dos termos marketing social e marketing societal decorre da errônea tradução dos termos originais, em inglês, optou-se pela concentração exclusiva sobre textos produzidos na língua portuguesa. As buscas foram realizadas em julho de 2016, utilizando os termos marketing social e marketing societal, individualmente. Os resultados encontrados nas plataformas foram filtrados em artigos publicados em periódicos classificados pelo Qualis 2014 no estrato de Administração, Ciências Contábeis e Turismo (ACT). Assim, desconsideraram-se os demais resultados encontrados, como relatórios, artigos apresentados em conferências, artigos publicados em periódicos não classificados no Qualis, dissertações e teses, dentre outros.

Os resultados da busca encontram-se expressos na Tabela 1, distribuídos em duas colunas: uma contemplando o total de resultados encontrados em cada plataforma e outra destacando apenas a quantidade dos artigos encontrados em periódicos classificados pelo Qualis no estrato de Administração, Ciências Contábeis e Turismo (ACT).

Tabela 1 - Resultados gerais do levantamento

\begin{tabular}{l|l|l|l|l}
\hline \multirow{2}{*}{ Local de busca } & \multicolumn{2}{|l|}{ Marketing social } & \multicolumn{2}{l}{ Marketing societal } \\
\cline { 2 - 5 } & Resultado geral & $\begin{array}{l}\text { Qualis } \\
\text { ACT }\end{array}$ & $\begin{array}{l}\text { Resultado } \\
\text { geral }\end{array}$ & $\begin{array}{l}\text { Qualis } \\
\text { ACT }\end{array}$ \\
\hline Capes & 20 & 15 & 4 & 4 \\
Scopus & 7 & 4 & 1 & 1 \\
Scielo & 11 & 9 & 1 & 1 \\
Spell & 118 & 116 & 17 & 17 \\
Proquest & 0 & 0 & 0 & 0 \\
Web of Science & 0 & 0 & 0 & 0 \\
\hline Total & 156 & 144 & 23 & 23 \\
\hline
\end{tabular}

Fonte: elaboração dos autores (2016).

Convém pontuar que as buscas englobaram todos os mecanismos permitidos por cada uma das plataformas. Dessa maneira, no Portal de Periódicos da Capes, realizou-se uma busca geral, filtrando os resultados por artigos; no Portal Scopus, a busca foi feita por título de artigo, abstract e palavras-chave; na plataforma Scielo, buscaram-se todos os índices; na plataforma Spell, buscou-se nas palavras-chave, título e resumo, neste último tendo sido necessário filtrar os artigos pelas expressões específicas de "marketing social" ou "marketing societal"; na plataforma Proquest, a busca também foi geral; por último, na plataforma Web of Science, buscou-se por título e por tópico.

A busca que mais apresentou resultados foi a da plataforma Spell, seguida dos Portais Capes, Scielo e Scopus. Por outro lado, as plataformas Proquest e Web of Science não 
retornaram nenhum resultado. Além disso, notou-se que o termo marketing social foi muito mais expressivo em resultados do que marketing societal.

Em resumo, o termo marketing social retornou 156 resultados, dos quais se identificaram, ao todo, 144 artigos publicados em periódicos classificados pelo Qualis, enquanto o termo marketing societal retornou 23 resultados, todos artigos publicados em periódicos classificados pelo Qualis. Como os demais resultados encontrados consistiam em artigos apresentados em conferências, artigos publicados em periódicos não classificados no Qualis, dissertações e teses, dentre outros, foram desconsiderados.

Além disso, do total de 144 artigos encontrados com o termo marketing social e publicados em periódicos classificados pelo Qualis no estrato ACT, resultaram 67, em virtude de casos de duplicidade identificados, posteriormente excluídos. Por sua vez, do total de 23 artigos encontrados com o termo marketing societal e publicados em periódicos classificados pelo Qualis no estrato ACT, resultaram 20, devido à eliminação de casos de duplicidade posteriormente identificados. Somando os resultados, têm-se 87 artigos.

Houve, ainda, 13 casos de duplicidade de artigos entre os termos, ou seja, artigos encontrados tanto na busca acerca do marketing social quanto naquela sobre marketing societal. Esses casos também foram eliminados dos 87 artigos selecionados, contabilizando 74 artigos resultantes. Por fim, desses 74 restantes, ainda quatro artigos foram excluídos por não conterem de fato, em nenhum momento, os termos abordados neste trabalho, resultando, assim, em 70 artigos selecionados para análise.

Posteriormente, a análise crítica dos conteúdos das publicações, realizada pela leitura dos artigos selecionados em comparação com os conceitos seminais e sua evolução identificados na pesquisa bibliográfica, permitiu identificar 42 artigos que fizeram uso equivocado dos termos, classificados em quatro grupos: a) artigos com desconformidades ou distorções de conceito, apresentando o conceito central do tema estudado não alinhado com o que consta na literatura; $b$ ) artigos contendo desconformidades ou distorções de acepção que, apesar de apresentarem o conceito alinhado com a literatura, desviaram-se dos preceitos do tema ao aplicarem-no ao objeto de estudo e fazerem análises posteriores; $c$ ) artigos que apresentaram desconformidades ou distorções de conceito e acepção, nos quais se verificaram, além do conceito em desacordo com a literatura, também a aplicação equivocada ao objeto de estudo e análises posteriores; e $d$ ) artigos que, apesar de apresentarem os termos em algum 
momento do trabalho, não os utilizaram de fato com nenhum sentido no texto, configurando uma desconformidade de forma.

Cabe esclarecer antecipadamente que o número de desconformidades supera bastante o número de artigos, pois muitos deles apresentam mais de uma desconformidade.

\section{ANÁLISE DOS ARTIGOS SELECIONADOS}

Analisando a data de publicação dos 70 artigos, observou-se um período de extensão considerável, que se inicia timidamente, com apenas 8 publicações entre as duas décadas de 1982 e 2002, mas ganha força entre os anos de 2003 e 2011, somando 27 publicações, conforme demonstrado na Tabela 2. O estudo dos termos revela-se ainda mais expressivo após esse período, com 35 publicações entre 2012 e 2016, até o momento da coleta dos artigos (julho).

Tabela 2 - Análise dos anos das publicações

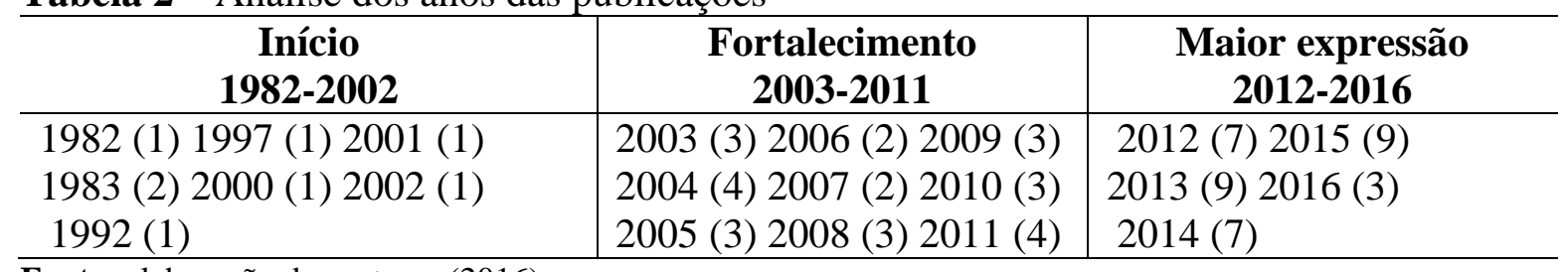

Fonte: elaboração dos autores (2016).

Os 70 artigos analisados foram publicados em 43 periódicos distintos, com destaque para a Revista Brasileira de Marketing - Remark, com nove publicações, e a Revista de Administração da USP - RAUSP, com cinco. Com menor expressão de frequência, três publicações cada, há a Revista Administração de Empresas - RAE, a Revista Alcance, a Revista Capital Científico, a Revista de Administração da Unimep e a Espacios.

Em relação à classificação dos periódicos, como se observa na Tabela 3, 13 artigos foram publicados em periódicos classificados como A2 no Qualis 2014 no estrato de ACT, 7 como B1, 15 como B2 e 27 como B3, além de 3 como B4 e 5 como B5. Convém lembrar que não existe, atualmente, nenhum periódico nacional da área de ACT classificado como A1 no Qualis. 
Tabela 3 - Análise dos títulos e classificações dos periódicos publicados

\begin{tabular}{|c|c|}
\hline Quantidade de artigos por título do periódico & $\begin{array}{l}\text { Quantidade de artigos por classificação } \\
\text { Qualis }\end{array}$ \\
\hline $\begin{array}{l}\text { - Revista Brasileira de Marketing/Remark - } 9 \\
\text { - Revista de Administração da USP/RAUSP - } \\
\text { - Revista Administração de Empresas/RAE - } \\
\text { - Revista Alcance - } 3 \\
\text { - Revista Capital Científico - } 3 \\
\text { - Revista de Administração da Unimep - } 3 \\
\text { - Espacios - } 3\end{array}$ & $\begin{array}{l}\mathrm{A} 2-13 \\
\mathrm{~B} 1-7 \\
\mathrm{~B} 2-15 \\
\mathrm{~B} 3-27 \\
\mathrm{~B} 4-3 \\
\mathrm{~B} 5-5\end{array}$ \\
\hline
\end{tabular}
Fonte: elaboração dos autores (2016).

Em relação à autoria, foram detectados 189 autores, 15 dos quais se repetiam pelo menos duas vezes, com destaque para Edson Coutinho Silva, com cinco publicações, assim como Silvio Augusto Minciotti e José Afonso Mazzon, com quatro publicações cada. Em menor expressão, com três publicações cada, encontram-se outros quatro autores: Francisco Giovanni David Vieira, Agnaldo Keiti Higuchi, Caissa Veloso Souza e Jefferson Rodrigues Pereira.

Quanto à metodologia de pesquisa adotada pelos artigos, pôde-se observar grande variação, predominando a abordagem qualitativa (28), com grande uso das técnicas de estudo de caso, entrevista em profundidade e/ou análise documental, além de alguns casos isolados de discussão em grupo e de uso da técnica Delphi. Em seguida, identificaram-se 21 ensaios teóricos, bem como 14 estudos com abordagem quantitativa, principalmente aplicando a técnica survey. Além disso, também se encontrou o método misto (6), com abordagem tanto qualitativa quanto quantitativa, em sua maioria com técnicas de entrevista combinada com survey, e uma bibliometria.

\subsection{Identificação da presença dos termos pesquisados nas palavras-chave}

Foram contabilizadas 249 palavras-chave nos 70 artigos analisados, das quais se destaca o termo marketing social (47), seguido de responsabilidade social (23) e variações similares. Outras palavras repetidas com frequência foram marketing (9) e marketing societal (8), além de palavras associadas a estratégia (7) e mudanças sociais (7), assim como a comportamento do consumidor (5) e sustentabilidade (5). 
Essas palavras-chave também foram analisadas em função da frequência de cada palavra componente, ou seja, quando uma palavra-chave continha mais de um elemento, cada um deles acabava contabilizado sozinho. Por exemplo, a palavra-chave responsabilidade social foi contabilizada como duas palavras isoladas: responsabilidade e social. Dessa forma, as 249 palavras-chave identificadas totalizaram 555 palavras, das quais as mais frequentes (que se repetiram pelo menos cinco vezes) foram: marketing e social, com 83 repetições cada uma; responsabilidade (22); comportamento (10); societal (8); corporativa (8) e corporativo (5); consumidor (7); sociais (6); além de causas, mudanças, saúde e sustentabilidade, com 5 repetições cada. Todas as palavras encontradas foram utilizadas para formar uma nuvem, realizada no site TagCrowd, conforme exposto na Figura 2.

Figura 2 - Nuvem das palavras encontradas nas palavras-chave dos artigos

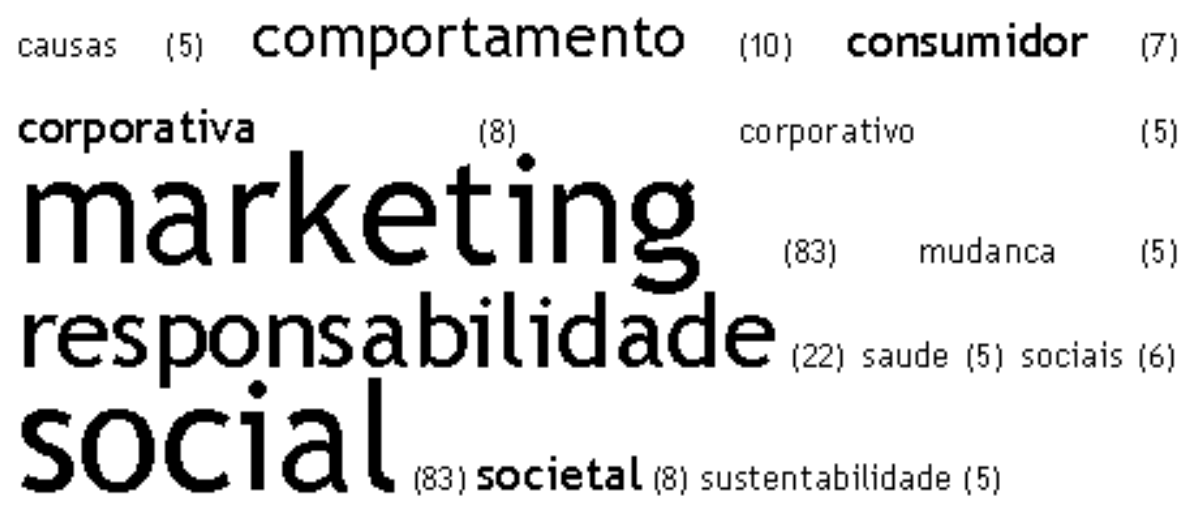

Fonte: elaboração dos autores (2016).

\subsection{Identificação da presença dos termos pesquisados nas denominações dos tópicos do referencial teórico}

Repetindo o procedimento de analisar a frequência de palavras para as denominações utilizadas nos títulos dos tópicos adotados ao organizar o referencial teórico, foram contabilizadas cerca de 1230 palavras, das quais se destacaram algumas mais frequentes, apresentadas na Figura 3, como: marketing e social, com 110 repetições cada; responsabilidade (26), corporativa (16) e sociais (15); conceito (10); Brasil, cidadania e societal, com 7 repetições cada; além de comportamento, doação, evolução e mudanças, com 6 repetições cada; bem como causas, consumidor, práticas e sustentável, com 5 repetições cada. 
Figura 3 - Nuvem das palavras encontradas nos títulos dos tópicos adotados ao organizar o referencial teórico

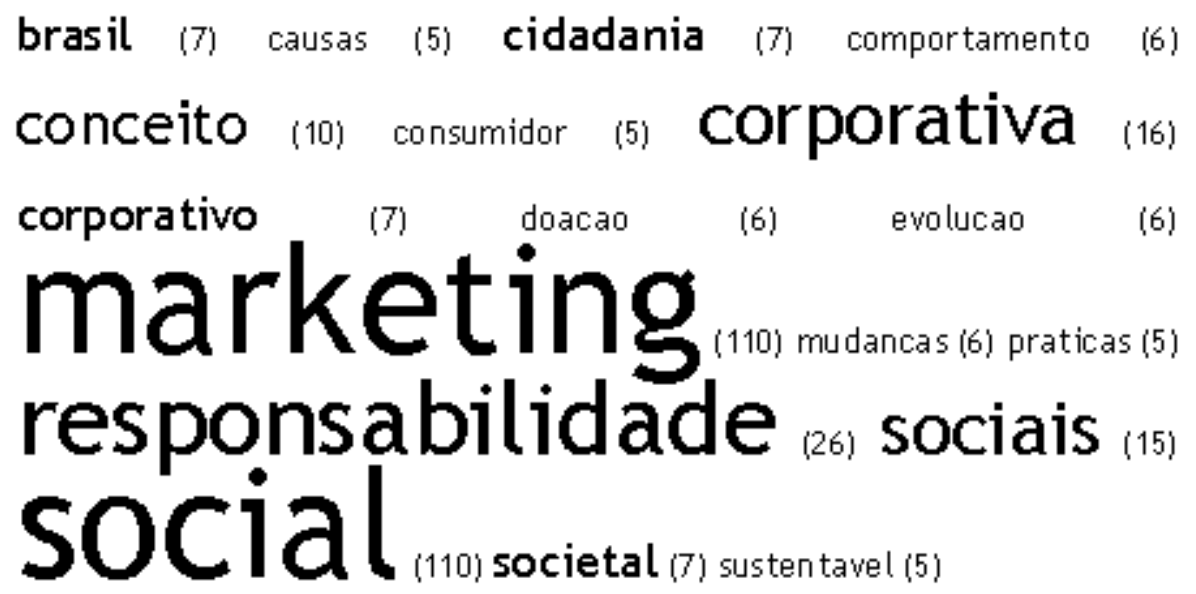

Fonte: elaboração dos autores (2016).

\subsection{Relação dos objetivos dos artigos analisados com os temas pesquisados}

Ao analisar os objetivos de pesquisa expostos pelos 70 trabalhos selecionados, foi possível observar algumas similaridades e, assim, classificá-los em seis blocos principais, conforme se observa no Quadro 1.

Quadro 1 - Análise e agrupamento dos objetivos expostos pelos trabalhos

1. Explicitamente marketing social -33

- Discussão teórica da origem, conceitos e contribuições - 16

- Identificação empírica da prática social - 6

- Plano ou programa social - 6

- Percepção das pessoas acerca das ações de marketing social - 4

- Avaliação do marketing social -3

2. Responsabilidade social -10

3. Campo social em geral -9

- Atividades, causas, posicionamento, consumo, mudanças, programa, dentre outros.

4. Explicitamente tanto ao marketing social quanto ao marketing societal -2

5. Explicitamente marketing societal -1

6. Outros diversos -14

- Marketing geral, marketing de relacionamento, marketing de serviços, marketing digital, dentre outros.

Fonte: elaboração dos autores (2016).

Primeiramente, nota-se uma predominância de objetivos relacionados explicitamente ao marketing social em 33 artigos, dos quais 2 abordaram a temática com a denominação de marketing relacionado a causas sociais e outros 3 trouxeram a questão do marketing social associado à responsabilidade social. Aprofundando a análise desse primeiro bloco, observou- 
se ainda que quatorze artigos se preocuparam em discutir teoricamente o tema de marketing social, abordando a origem, conceitos e contribuições, bem como seis artigos tiveram como intuito identificar empiricamente a prática social e outros seis se concentram na questão do plano ou programa social. Além disso, outros quatro artigos buscaram analisar a percepção das pessoas acerca das ações de marketing social, e outros três concentraram-se em avaliar o marketing social.

Em segundo lugar, aparecem dez objetivos relacionados à responsabilidade social, seguido de nove relacionados a demais fatores do campo social em geral, com uso de palavras como atividades, causas, posicionamento, consumo, mudanças, programa, dentre outras. Com menor expressão, têm-se dois objetivos que se referem explicitamente tanto ao marketing social quanto ao societal, assim como um que se vincula explicitamente ao marketing societal. Outros quatorze objetivos abordam questões diversas da temática de interesse deste estudo, assim como um não traz um objetivo explícito, tampouco foi possível deduzi-lo por conta própria.

\subsection{Identificação de distorções no emprego dos termos analisados}

Ao analisar os referenciais teóricos, as análises e discussões de resultados e as conclusões ou considerações finais dos 70 artigos selecionados, verificaram-se distorções e/ou desconformidades em 42 deles, algumas impactando substancialmente o entendimento do tema abordado.

Nesse sentido, os tipos de desconformidades apresentadas permitiram classificar os artigos com uso equivocado dos termos em quatro grupos: a) artigos que apresentaram desconformidades ou distorções de conceito (4); $b$ ) artigos que apresentaram desconformidades ou distorções de acepção (21); c) artigos que apresentaram desconformidades ou distorções de conceito e acepção (13); e $d$ ) artigos que, apesar de apresentarem os termos em algum momento do trabalho e serem identificados na busca, não os utilizaram de fato com nenhum sentido no texto, configurando uma desconformidade de forma (4).

No primeiro grupo, dentre os quatro artigos com desconformidades ou distorções de conceito, o principal problema identificado relaciona-se com os conceitos de marketing social e marketing societal. Enquanto estes foram, em alguns casos, tratados como sinônimos ou como se existisse um único conceito para os dois termos, predominando o conceito de marketing 
social, em outras situações, havia um conceito misto baseado nos dois termos originais. Cabe pontuar que esses artigos foram publicados em periódicos de relevância acadêmica (sendo três B1 e um B2).

Quadro 2 - Síntese das desconformidades de conceito (4 artigos)

\begin{tabular}{|l|l|}
\hline Confunde marketing social com marketing societal & 2 \\
\hline Confunde marketing social com filantropia & 1 \\
\hline Confunde marketing social com marketing ecológico (sic) e responsabilidade social & 1 \\
\hline Confunde marketing societal com responsabilidade social & 1 \\
\hline Confunde marketing social com propaganda institucional & 1 \\
\hline
\end{tabular}

Fonte: elaboração dos autores.

Obs.: Alguns artigos apresentaram mais de uma desconformidade

Em segundo lugar, quanto ao emprego dos termos nos trabalhos, podem-se notar, com base no Quadro 3, diversas desconformidades de acepção apenas em relação a marketing social. Com certa frequência, verifica-se sua aplicação ou sugestão de aplicação como ferramenta apropriada para divulgar ações institucionais ou de responsabilidade social realizadas por organizações, visando a uma maior visibilidade da marca ou a alguma projeção no mercado que lhes garantam maior competitividade diante de um público específico. Essa é uma visão muito mais comprometida com os resultados comerciais e, portanto, bem mais próxima da aplicação do marketing tradicional. Soma-se a isso o uso do termo para referir-se quer à destinação de um percentual de venda a uma causa, quer a doações esporádicas a uma causa ou obra social, em ambos os casos com objetivo de dar visibilidade à marca ou aproximá-la de um mercado específico. Outra desconformidade frequente de acepção é estudar casos de organizações ou programas educacionais ou de sensibilização como exemplos de marketing social, quando na verdade não o são, conforme explanado por Silva e Mazzon (2016). Pela quantidade de artigos que se enquadraram nessa categoria (21), houve diversidade quanto à relevância acadêmica dos periódicos, sendo a maioria, porém, de menor relevância (cinco B2, nove B3, um B4 e um B5). Apesar disso, deve-se ressaltar também a localização de cinco artigos de alta relevância, o que se mostra bastante preocupante (quatro A2 e um B1).

Quadro 3 - Síntese das desconformidades de acepção (21 artigos)

\begin{tabular}{|l|l|}
\hline Exemplos usados não evidenciam causa social & 1 \\
\hline Confundem marketing social com responsabilidade social & 7 \\
\hline Confundem marketing social com propaganda institucional & 7 \\
\hline Confundem marketing social com marketing societal & 8 \\
\hline Confundem marketing social com filantropia & 1 \\
\hline Confundem marketing social corporativo com responsabilidade social & 1 \\
\hline
\end{tabular}

Fonte: elaboração dos autores (2016).

Obs.: Alguns artigos apresentaram mais de uma desconformidade 
No terceiro grupo, exposto no Quadro 4, nos treze artigos que apresentaram desconformidades tanto de conceito quanto de acepção, verificam-se principalmente a conceituação e aplicação do marketing social como sinônimo de responsabilidade social e marketing relacionado a causas sociais, além do emprego do termo marketing social corporativo. Ambos se relacionam, por vezes, com o objetivo de dar visibilidade a certa marca ou aproximá-la de um mercado específico ao destinar, a uma causa ou obra social, um percentual de venda ou doações esporádicas. Em outras ocasiões, os termos designam mecanismos do marketing voltados a mudar comportamentos em relação à aceitação de produtos, o que configura essencialmente a aplicação do conceito mais ortodoxo do marketing. Existe ainda o tratamento de marketing social como sinônimo de marketing ecológico e marketing societal, sem, no entanto, representar uma preocupação genuína da organização quanto à sustentabilidade de seus processos, conforme argumentado por Silva, Minciotti e Romeiro (2011), mas tão somente visando à associação de sua marca a uma causa ambiental. Desse grupo também se podem identificar a conceituação e a análise de marketing societal como sinônimo de filantropia. Também aqui, devido à quantidade de artigos presentes, observou-se certa diversidade na relevância acadêmica dos periódicos, ainda que em menor grau, novamente com a maioria dos artigos consistindo em publicações de menor relevância (um B2, cinco B3, dois B4 e um B5); apesar disso, ressalta-se também a presença de três artigos de alta relevância (dois A2 e um B1).

Quadro 4 - Síntese das desconformidades tanto por conceito quanto por acepção (13 artigos)

\begin{tabular}{|l|l|}
\hline Confundem marketing social com marketing societal & 5 \\
\hline Confundem marketing social com marketing social corporativo & 1 \\
\hline Confundem marketing social com responsabilidade social & 8 \\
\hline Confundem marketing social com propaganda institucional & 1 \\
\hline Confundem marketing societal com marketing social corporativo & 2 \\
\hline Confundem marketing social corporativo com responsabilidade social & 1 \\
\hline Confundem marketing social com relações públicas & 1 \\
\hline Confundem marketing social com filantropia & 1 \\
\hline O caso analisado não é compatível com o conceito & 1 \\
\hline
\end{tabular}

Fonte: elaboração dos autores (2016).

Obs.: Alguns artigos apresentaram mais de uma desconformidade

Por fim, as desconformidades de forma se referem a quatro artigos que, apesar de apresentarem os termos em algum momento do trabalho e serem identificados na busca, não os utilizaram de fato com nenhum sentido no texto, o que evidencia a utilização indiscriminada dos termos pela academia, principalmente marketing social, como representativo de qualquer 
relação existente entre empresas e a sociedade (Quadro 5). Esses artigos foram publicados em periódicos de menor relevância acadêmica (sendo três B3 e apenas um B1).

Quadro 5 - Síntese das desconformidades de forma (4 artigos)

\begin{tabular}{|l|l|}
\hline Apenas mencionam marketing social no título & 1 \\
\hline Apenas mencionam marketing social no resumo & 2 \\
\hline $\begin{array}{l}\text { Apresentam marketing societal como evolução de marketing, sem conexão com } \\
\text { o texto }\end{array}$ & 1 \\
\hline
\end{tabular}

Fonte: elaboração dos autores (2016).

Desse modo, pôde-se observar que a metade dos artigos analisados apresentou desconformidades ou distorções de acepção. Isso quer dizer que, embora os autores tenham discorrido teoricamente sobre os conceitos conforme a literatura seminal, verificaram-se falhas em suas aplicações. Tal resultado sugere certa incapacidade de depreender a teoria na prática de forma adequada, ilustrando um provável distanciamento entre ambas essas esferas. Em segundo lugar, ressaltaram-se os artigos com desconformidades ou distorções tanto de conceito quanto de acepção. Esse resultado indica incongruência teórica e prática, sugerindo uma falha na compreensão dos conceitos e, talvez por conta disso, uma incapacidade de aplicá-los corretamente. Em menor número, localizaram-se os artigos somente com desconformidades ou distorções de conceito, novamente evidenciando a falta de compreensão dos conceitos discorridos e debatidos pelos autores. Em igual quantidade, observaram-se os artigos com desconformidades de forma, considerados de impacto menor sobre a propagação de eventuais distorções dos termos estudados, bem como publicados em periódicos de menor relevância.

Conforme exposto na Tabela 4, é possível correlacionar com o ano de publicação: a) a quantidade de artigos com desconformidades ou distorções; e b) a classificação Qualis do periódico. A primeira análise leva a conclusões preocupantes porque, apesar da predominância de desconformidades encontrados em periódicos com classificação Qualis B3, os periódicos mais bem classificados também contemplam essa distorção, de forma até expressiva. 
Tabela 4 - Análise das desconformidades encontradas por período e classificações dos periódicos de publicação

\begin{tabular}{|c|c|c|c|}
\hline \multicolumn{3}{|c|}{$\begin{array}{l}\text { Quantidade de artigos com desconformidade por período } \\
\text { de publicação }\end{array}$} & \multirow{2}{*}{$\begin{array}{l}\text { Quantidade de artigos com } \\
\text { desconformidade por } \\
\text { classificação Qualis }\end{array}$} \\
\hline $\begin{array}{l}\text { Início } \\
1982-2002(4)\end{array}$ & $\begin{array}{l}\text { Fortalecimento } \\
2003-2011(20)\end{array}$ & $\begin{array}{l}\text { Maior expressão } \\
\text { 2012-2016 (18) }\end{array}$ & \\
\hline $\begin{array}{l}1997(1) \\
2000(1) \\
2001(1) \\
2002(1)\end{array}$ & $\begin{array}{l}2003(1) 2004(2) \\
2005(2) 2006(1) \\
2007(2) 2008(3) \\
2009(3) 2010(3) \\
2011(3)\end{array}$ & $\begin{array}{l}2012(4) \\
2013(5) \\
2014(4) \\
2015(5)\end{array}$ & $\begin{array}{l}\mathrm{A} 2-6 \\
\mathrm{~B} 1-4 \\
\mathrm{~B} 2-8 \\
\mathrm{~B} 3-19 \\
\mathrm{~B} 4-3 \\
\mathrm{~B} 5-2\end{array}$ \\
\hline
\end{tabular}

Fonte: elaboração dos autores (2016).

Além disso, constata-se que 50\% das publicações ocorridas no período inicial (19822002) apresentavam equívocos ou distorções de natureza conceitual, de forma ou de acepção no uso dos termos aqui estudados. No período em que se fortaleceu o interesse pelos assuntos em pauta (2003-2011), cresceu também a incidência das distorções, atingindo 74\% dos artigos publicados. Em contrapartida, houve um abrandamento das desconformidades ou imprecisões conceituais, formais ou de acepção referentes ao uso dos termos marketing social e marketing societal nos textos publicados no período de maior expressão da ocorrência de publicações (2012-2016), atingindo 51\% desses artigos. De qualquer forma, continua marcante e preocupante a incidência de textos acadêmicos contribuindo para a desinformação acerca do que seja marketing social e marketing societal.

\section{CONSIDERAÇÕES FINAIS}

O estudo do marketing social e do marketing societal, em língua portuguesa, iniciou-se ainda na década de 1980, somando, até o momento, expressiva produção científica, em vista principalmente da boa classificação dos periódicos analisados. Também se identificou significativa disseminação de ambos os conceitos, com grande diversidade tanto de autores quanto de periódicos em que os artigos foram publicados.

Apesar disso, foram notórias as desconformidades identificadas no emprego dos conceitos, principalmente em contextos de sua aplicação. Apesar de claro o contexto histórico de seu surgimento, de sua evolução ao longo dos anos e do conceito estabelecido e aceito pela literatura em seu estado da arte, a teoria tem sido aplicada de forma equivocada. Além disso, também são numerosos os artigos que transmitem desconformidades tanto de concepção quanto 
de acepção, indicando falta de compreensão teórica e prática. Tais desconformidades permeiam todos os estratos de classificação dos periódicos, incluindo aqueles de relevância praticamente incontestável (como o estrato A2).

Para que não restem dúvidas, a revisão da literatura apresentada evidencia o marketing social como aplicação do composto de marketing, em sua forma mais próxima ao marketing tradicional, com fim específico de promover uma ideia socialmente justa ou uma mudança de comportamento em benefício da coletividade. Por outro lado, o marketing societal expõe uma evolução conceitual do marketing, que passa a considerar aspectos relacionados à sustentabilidade do negócio, produto ou serviço ofertado e das próprias ações de marketing aplicadas a seu favor.

A profusão de termos e conceitos atualmente utilizados para descrever diversas áreas do marketing contribui demasiadamente para as distorções encontradas, fato que requer maior cautela de pesquisadores, editores e avaliadores de periódicos ao conceber ou analisar as aplicações correspondentes. É necessário e urgente que a academia, de forma geral, e as publicações acadêmicas, mais especificamente, adotem de forma rigorosa os conceitos, acepções e formas de uso apresentados na literatura seminal que introduziu os termos marketing social e marketing societal no arcabouço teórico de marketing.

Dessa maneira, o trabalho contribui para a área de marketing ao apontar a existência de um problema grave nas pesquisas relacionadas àqueles temas, com possíveis consequências sobre a validade dos estudos, mas sobretudo ao reconhecer a necessidade de uma maior reflexão sobre a aplicação dos diferentes enfoques da área. Estudos futuros que abordem as origens ou principais fatores que incidem sobre tantas desconformidades podem elucidar melhor os caminhos a serem seguidos para solucionar a confusão apontada. 


\section{REFERÊNCIAS}

ANDREASEN, A. R. Social marketing in the 21st Century. Thousand Oaks: Sage, 2006.

BARBOSA, S. I. S.; COSTA, F. J. Marketing social para Doação de Sangue: análise da predisposição de novos doadores. Cad. Saúde Pública, v. 30, n. 7, p. 1463-1474, 2014.

BERGEL, E.; BRANDÃO, M. M.; FREIRE, O. L.; BIZÁRRIAS, F. S. Relação entre Marketing e RSAE nos Congressos da Anpad: Estudo Bibliométrico de 1998-2012. Revista de Administração da UNIMEP, v. 13, n. 1, p. 189-219, 2015.

BLOOM, P. N.; NOVELLI, W. D. Problems and Challenges in Social Marketing. Journal of Marketing, v. 45, n. 2, p. 79-88, 1981.

FELDMAN, L. P. Societal Adaptation: A New Challenge for Marketing. Journal of Marketing, v. 35, n. 3, p. 54-60, 1971.

KOTLER, P. Marketing para organizações sem fins lucrativos. São Paulo: Atlas, 1978.

KOTler, P.; ARMStrong, G. Princípios de Marketing. 12. ed. São Paulo: Pearson Prentice Hall, 2007.

KOTLER, P.; KELLER, K. L. Administração de Marketing. 14. ed. São Paulo: Pearson Education do Brasil, 2012.

KOTLER, P.; LEE, N. R. Marketing contra a pobreza. Porto Alegre: Bookman, 2010.

KOTLER, P.; LEVY, S. J. Broadening the Concept of Marketing. Journal of Marketing, v. 33. n. 1, p. 10-15, $1969 a$.

KOTLER, P.; LEVY, S. J. A New Form of Marketing Myopia: Rejoinder to Professor Luck. Journal of Marketing, v. 33, n. 3, p. 55-57, $1969 \mathrm{~b}$.

KOTLER, P.; ZALTMAN, G. Social Marketing: An Approach to Planned Social Change. Journal of Marketing, v. 35, n. 3, p. 3-12, 1971. 
LACZNIAK, G. R.; LUSCH, R. F.; MURPHY, P. E. Social Marketing: Its Ethical Dimensions. Journal of Marketing, v. 43, n. 2, p. 29-36, 1979.

LAVIDGE, R. J. The Growing Responsibilities of Marketing. Journal of Marketing, v. 34, n. 1, p. 25-28, 1970.

LUCK, D. J. Broadening the Concept of Marketing - too far. Journal of Marketing, v. 33, n. 3, p. 53-63, 1969.

LUCK, D. J. Social Marketing: Confusion Compounded. Journal of Marketing, v. 38, n. 4, p. 70-72, 1974.

MARTINS, O. M. D.; PAÇO, A. M.; MAINARDES, E. W.; RODRIGUES, R. G. O marketing social e a promoção de mudanças estruturais no aleitamento materno. Revista de Administração de Empresas - RAE, v. 54, n. 4, p. 370-380, 2014.

MCKENZIE-MOHR, D.; SMITH, W. Fostering sustainable behavior: an introduction to community-based social marketing. New society publishers, 1999.

MORAIS, M. R. B.; GIULIANI, A. C.; FARAH, O. E.; SPERS, E. Marketing societal e marketing social: uma visão empresarial. Revista Ciências Administrativas, v. 11, n. 2, p. 241-249, 2005.

SCHNEIDER, G.; LUCE, F. B. Marketing social: abordagem histórica e desafios contemporâneos. Revista Brasileira de Marketing - ReMark, v. 13, n. 3, p. 125-137, 2014.

SILVA, E. C.; MAZZON, J. A. Plano de marketing social para a promoção da saúde: desenvolvimento de políticas de saúde pública orientada ao "cliente". Revista Brasileira de Marketing - ReMark, v. 15, n. 2, p. 164-176, 2016.

SILVA, E. C.; MINCIOTTI, S. A. Marketing Ortodoxo, Societal e Social: As Diferentes Relações de Troca com a Sociedade. Revista Brasileira de Gestão de Negócios, v. 7, n. 17, p. 15-22, 2005.

SILVA, E. C.; MINCIOTTI, S. A.; GIL, A. C. Resgatando o Conceito de marketing social. APGS - Administração Pública e Gestão Social, v. 5, n. 2, p. 63-77, 2013. 
SILVA, E. C.; MINCIOTTI, S. A.; ROMEIRO, M. C. marketing societal: uma contribuição para o crescimento sustentável das organizações. Rev. Adm. UFSM, v. 4, n. 1, p. 19-38, 2011.

TAKAS, A. Societal Marketing: A Businessman's Perspective. Journal of Marketing, v. 38, n. 4, p. 2-7, 1974.

TAVARES, A. T.; ESPANHA, R. marketing social: de curto passado a futuro promissor. Revista Portuguesa e Brasileira de Gestão, v. 14, n. 3, p. 26-36, 2015.

TREINTA, F. T.; FARIAS FILHO, J. R.; SANT'ANNA, A. P.; RABELO, L. M. Metodologia de pesquisa bibliográfica com a utilização de método multicritério de apoio à decisão. Production, v. 24, n. 3, p. 508-520, 2014. 